Exp. Anim. 50(1), 91-95, 2001

\title{
Effect of Acetylcholinesterase Activity on Pathogenesis of Airway Hyperresponsiveness in Guinea Pigs
}

\author{
Hiromi KADOTA ${ }^{1)}$, Masayoshi KUWAHARA ${ }^{1)}$, Ryoji NISHIBATA2), \\ Hiroki MIKAMI2), and Hirokazu TSUBONE ${ }^{1)}$
}

\begin{abstract}
1)Department of Comparative Pathophysiology, Graduate School of Agricultural and Life Sciences, The University of Tokyo, 1-1-1 Yayoi, Bunkyo-ku, Tokyo 113-8657 and ${ }^{2}$ Institute of Bio-Active Science, Nippon Zoki Pharmaceutical, Hyogo 673-1461, Japan
\end{abstract}

\begin{abstract}
To clarify the effect of acetylcholinesterase (AChE) on the pathogenesis of airway hyperresponsiveness, AChE activities in tracheal smooth muscle and lung tissue from congenitally bronchial-hypersensitive (BHS) and bronchial-hyposensitive (BHR) guinea pigs were compared. For this purpose, AChE activities were determined by measuring the rate of absorbance of tisssue homogenate. Relative amounts of AChE mRNA were also evaluated by the RT-PCR method. In both tracheal smooth muscle and lung tissue from $B H S$, the AChE activity and the relative amount of AChE mRNA were less than those in $B H R$. These results suggest that the reduced AChE activity is at least a candidate for inducing airway hyperresponsiveness.
\end{abstract}

Key words: acetylcholinesterase, lung tissue, tracheal smooth muscle

Airway hyperresponsiveness is one of the most important features of the development of asthma, and may precede the expression of the asthmatic phenotype [8, 9]. It is likely that airway hyperresponsiveness is effected by several genes and that each gene contributes to the continuous variation seen between a normal population and asthmatics [5]. Acetylcholinesterase (AChE) is the main cholinesterase in the tracheal smooth muscle and ganglia of guinea pig, rat, dog and so on $[11,13$, 14]. The role of $\mathrm{AChE}$ in regulating cholinergic synapses is rapid hydrolysis of acetylcholine (ACh) into choline and acetate [1-3] so that changes in AChE activity may be related to the pathogenesis of airway hyperresponsiveness.
The two strains of guinea pigs, bronchial-hypersensitive (BHS) and bronchial-hyposensitive (BHR) guinea pigs (Nippon Zoki Pharmaceutical Co., Ltd. Hyogo, Japan) are developed by selective breeding techniques from the Hartley strain that is, all BHS fell down within $90 \mathrm{sec}$ in a screening test with $0.08 \% \mathrm{ACh}$ aerosol exposure at 8 weeks old, but no BHR showed fell down for at least $10 \mathrm{~min}$. Because AChE activity may affect this different responsiveness of BHS and BHR to ACh, these guinea pig strains ( $\mathrm{n}=15$ each, B.W. 400-750 g) were used to elucidate the effect of AChE on the pathogenesis of airway hyperresponsiveness in this model.

To investigate AChE activities, the trachea and lungs were excised from guinea pigs killed by stunning and

(Received 10 March 2000 / Accepted 26 July 2000)

Address corresponding: M. Kuwahara, Department of Comparative Pathophysiology, Graduate School of Agricultural and Life Sciences, The University of Tokyo, 1-1-1 Yayoi, Bunkyo-ku, Tokyo 113-8657, Japan 
exanguination. Each kind of tissue was homogenized at $4^{\circ} \mathrm{C}$ in a homogenizer (WHEATON overhead stirrer, NJ, USA) and added to PBS ( $8 \mu l$ of buffer $/ \mathrm{mg}$ of tissue). AChE activity was determined by measuring the absorbance rate in tissue homogenates according to the methods of Mitchell et al. [11]. Briefly, acetylthiocholine was used as a substrate for AChE. Thiocholine is produced by hydrolysis of acetylthiocholine and reacts with 5,5-dithiobis (nitrobenzoic) acid [DTNB] to produce 2-nitro-5 mercapto-benzoate. To determine AChE activity, 164 $\mu l$ of PBS (containing $0.24 \mathrm{mM}$ DTNB) was added to microplate wells $(200 \mu l)$. The microplates were warmed to $37^{\circ} \mathrm{C}$ in an incubator. Then $24 \mu \mathrm{l}$ of homogenate and $12 \mu \mathrm{l}$ of substrate were added to the wells. These mixtures were incubated for an hour. During and after incubation, the rate of production of 2-nitro-5 mercapto-benzoate was measured at $405 \mathrm{~nm}$ wavelength on a Microplate Reader (BioRad Model 550, Bio-Rad Laboratories, California, USA). The amount of protein in the homogenates was determined with BCA Protein Assay Reagent (PIERCE, Illinois, USA).

As shown in Fig. 1, the values of absorbance units $(\mathrm{AU}) / \mathrm{h} / \mathrm{mg}$ protein in homogenates from BHS and BHR

(a)

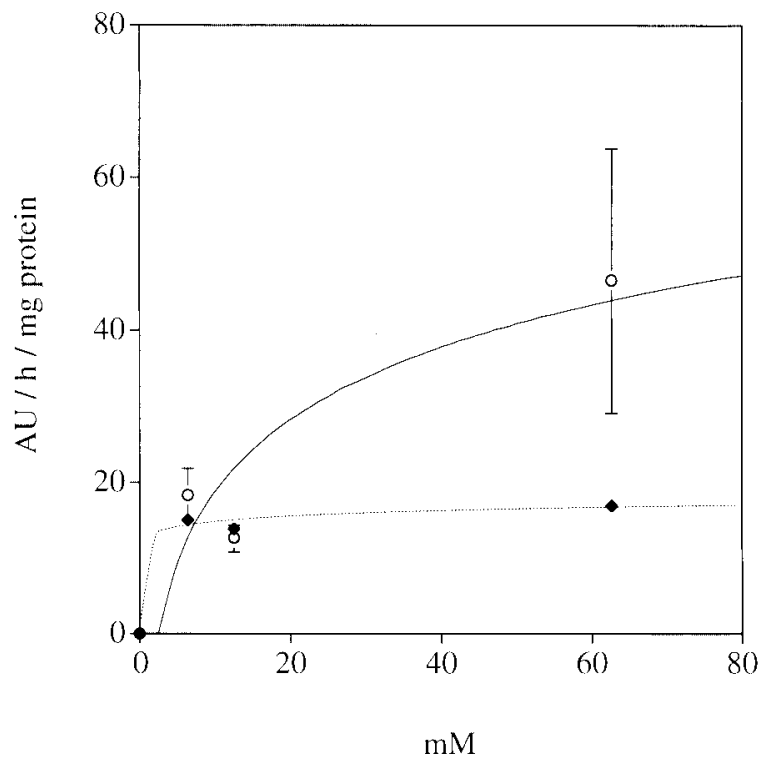

increased in a concentration-dependent manner. Curve fitting was done by a logarithmic method. Homogenates of tracheal smooth muscle (Fig. 1a) and lung tissue (Fig. 1b) from BHS had a substantially reduced absorbance rate compared to BHR. In lung tissue at 62.4 $\mathrm{mM}$ substrate, the maximal rate of $\mathrm{AChE}$ activity in BHS was significantly less $(13.5 \pm 0.65 \mathrm{AU} / \mathrm{h} / \mathrm{mg}$ protein) than those in BHR $(17.7 \pm 0.79 \mathrm{AU} / \mathrm{h} / \mathrm{mg}$ protein; $\mathrm{P}<0.001)$. In tracheal smooth muscle at $62.4 \mathrm{mM}$ substrate, the maximal rate of AChE activity in BHS was less (17.0 $\pm 1.15 \mathrm{AU} / \mathrm{h} / \mathrm{mg}$ protein) than in BHR (46.5 $\pm 17.3 \mathrm{AU} / \mathrm{h} / \mathrm{mg}$ protein). These results suggested that a distinctly greated reduction in AChE activities occurred in tracheal smooth muscle and lung tissue from BHS than in those from BHR.

Kinetic analysis was also studied in samples from lung tissue as shown in Fig. 2. AChE activity $\left(\mathrm{V}_{\max }\right)$ in homogenates of lung tissue from BHS $(12.3 \pm 0.58$ $\mathrm{AU} / \mathrm{h} / \mathrm{mg}$ protein) was significantly less than in those from BHR (16.8 $\pm 0.96 \mathrm{AU} / \mathrm{h} / \mathrm{mg}$ protein; $\mathrm{P}=0.002)$. The $\mathrm{K}_{\mathrm{m}}$ values, Michaelis's constants for AChE in homogenates of lung tissue from BHS $(1.10 \pm 0.29 \mathrm{M})$ and BHR $(1.13 \pm 0.30 \mathrm{M})$ were almost the same. Maximal AChE activity $\left(\mathrm{V}_{\max }\right)$ was significantly less in lung

(b)

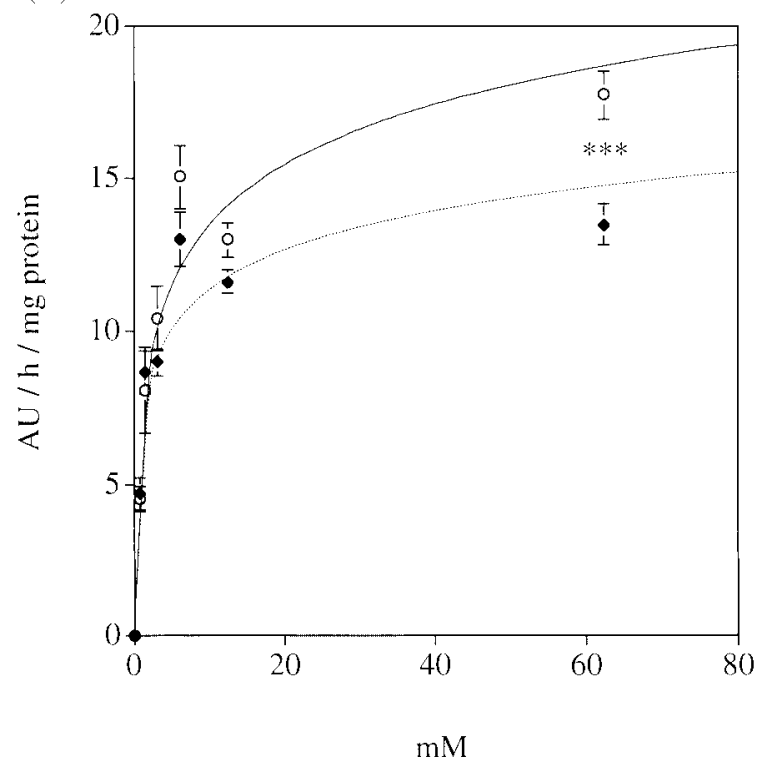

Fig. 1. AChE activity versus the substrate concentration for homogenates from tracheal smooth muscle (a) and lung tissue (b). AChE activities are expressed as absorbance units $(\mathrm{AU}) / \mathrm{h} / \mathrm{mg}$ protein. The values are the mean $\pm \mathrm{SE}$ from 7 separate experiments. Curve fitting was done by a logarithmic method. BHS, closed diamond; BHR, open circle. $* * * \mathrm{P}<0.001$ BHS vs BHR. 
tissue from BHS than from BHR, but the $K_{m}$, Michaelis's constant values for AChE were similar for BHS and BHR so that isoforms having different activity were unlikely to be present and a decrease in a single AChE isoform activity caused increasing airway hyperresponsiveness to ACh in BHS.

Relative amounts of AChE mRNA in tracheal smooth muscle and lung tissue were also measured. Total RNA samples were isolated with a Catrimox-14 ${ }^{\mathrm{TM}} \mathrm{RNA}$ isolation kit ver 2.11 (TaKaRa Biomedicals, Shiga, Japan) and were treated with DNase I (TaKaRa). The samples

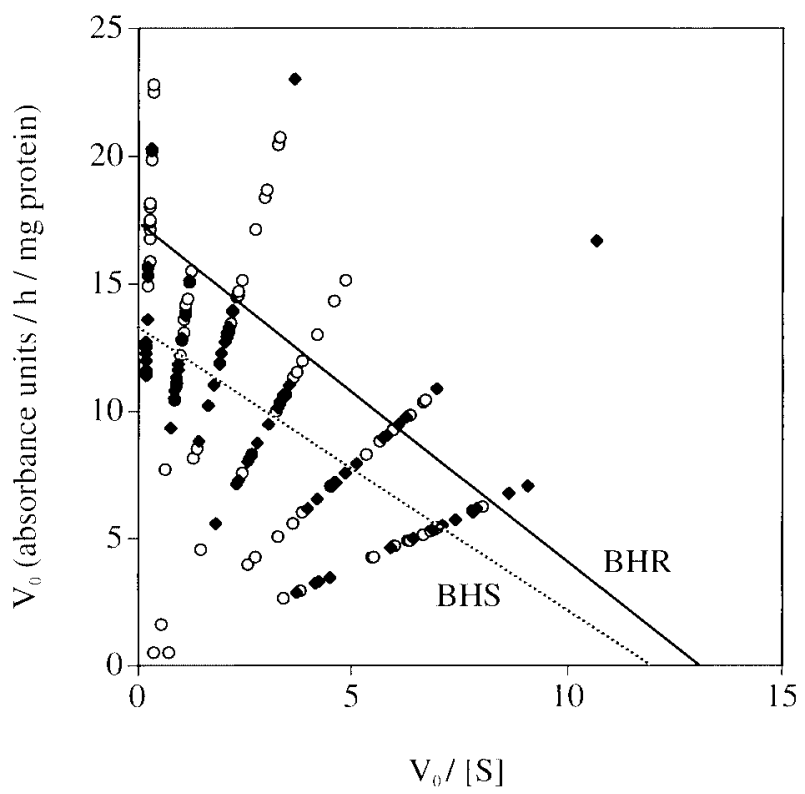

Fig. 2. Mean Eadie-Hofstee plots for data of lung tissue derived from substrate concentration-dependence studies (Fig. 1b). AChE activity (absorbance units/ $\mathrm{h} / \mathrm{mg}$ protein) is plotted as $\mathrm{V}_{0}$. $\mathrm{S}=$ substrate (acetylthiocholine) concentration in the microplate well. Michaelis constants $\left(\mathrm{K}_{\mathrm{m}}\right)$ are similar for AChE from BHS and BHR, but homogenates of lung tissue from BHS demonstrated significantly reduced $\mathrm{V}_{\max }$ values $(\mathrm{P}<0.001)$. BHS, closed diamond; BHR, open circle. were added to a RNA PCR Kit Ver 2.1 (TaKaRa), then incubated at $50^{\circ} \mathrm{C}$ for $35 \mathrm{~min}$, at $95^{\circ} \mathrm{C}$ for $5 \mathrm{~min}$ (deactivation of AMV reverse transcriptase), and at $5^{\circ} \mathrm{C}$ for 5 min in a thermal cycler (PCR Thermal Cycler PERSONAL, TaKaRa).

The primers used for AChE and GAPDH were designed on the basis of the coding sequence obtained from the GenBank database for rat/mouse AChE and guinea pig GAPDH (synthesized by Amersham Pharmacia Biotech, Tokyo, Japan). Table 1 shows the sequences of forward and reverse primers and expected product size. The samples were pre-incubated at $94^{\circ} \mathrm{C}$ for $10 \mathrm{~min}$ and then cycled for 40-50 times as follows: $94^{\circ} \mathrm{C}$ for $30 \mathrm{sec}, 63.6^{\circ} \mathrm{C}$ for $\mathrm{AChE}$ (or $64.0^{\circ} \mathrm{C}$ for GAPDH) for $30 \mathrm{sec}$ and $72^{\circ} \mathrm{C}$ for $1.5 \mathrm{~min}$. To quantify the amount of mRNAs, $20 \mu l$ of PCR products was taken up at 45 and 50 cycles.

A volume of $5 \mu l$ of the reaction mixture (with $2 \mu l$ of loading buffer, Novagen, WI, USA) was loaded onto 3\% agarose gels (Funakoshi, Tokyo, Japan) and subjected to electrophoresis and then dyed with ethylenebromide (10 pM). Digitized images of the gels were obtained with a CCD image analyzer (FULA-3000, FUJIFILM, Tokyo, Japan) and all data were analyzed on a computer with the public-domain program NIH Image. The peak area of each cDNA was measured as peak area. Band intensity was normalized with an intensity marker of $300 \mathrm{bp}$ in the same gels. To compare relative amounts of mRNA in BHS and BHR, all data were standardized with GAPDH that was used as an internal control.

As shown in Fig. 3a, the amounts of cDNA obtained from tracheal smooth muscle at 45 cycles were less than those at 50 cycles and the values at 45 cycles were used for analysis. In Fig. 3b, the AChE mRNA/GAPDH mRNA value in BHS was significantly less $(0.45 \pm$ $0.07)$, than those in BHR $(0.82 \pm 0.17, \mathrm{P}<0.05)$ in tracheal smooth muscle. In lung tissue, the value in BHS

Table 1. Primer sequences used for RT-PCR

\begin{tabular}{clllllllll}
\hline Target & & \multicolumn{10}{c}{ Sequence $\left(5^{\prime}-3^{\prime}\right)$} & & Expected size \\
\hline Acetylcholinesterase & forward & gca & gca & ata & tgt & gag & cct & ga & $197 \mathrm{bp}$ \\
& reverse & ggt & cga & act & ggt & tct & tcc & ag & \\
\multirow{2}{*}{ GAPDH } & forward & gag & ctg & aat & ggg & aag & ctc & ac & $199 \mathrm{bp}$ \\
& reverse & cgc & tgt & tga & agt & cac & agg & ac & \\
\hline
\end{tabular}


(a)

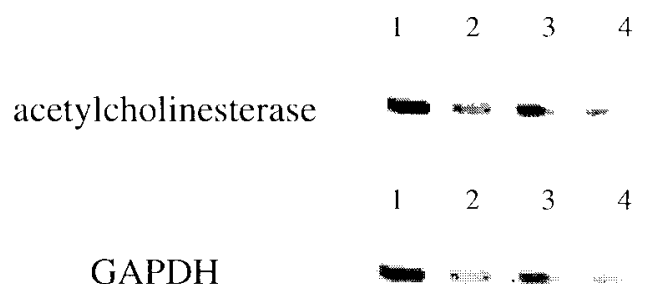

(b)

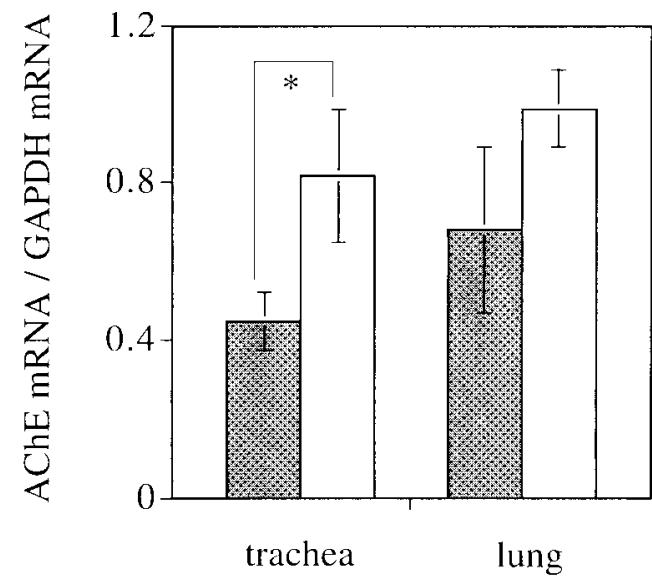

Fig. 3. Figure 3a shows the result for RT-PCR in tracheal smooth muscle from BHS and BHR. Lanes 1 and 2 represent BHS samples and the lanes 3 and 4 represent BHR samples. The amounts of each cDNA at 45 cycles (lanes 2 and 4 ) are less than those at 50 cycles (lanes 1 and 3), and the values at 45 cycles were used for analysis. Fig. 3b shows the relative values for AChE mRNA in tracheal smooth muscle and lung from BHS and BHR. AChE mRNA was normalized to GAPDH mRNA. Each value is the mean \pm SE for 8 samples. BHS, gray bar; BHR, open bar. $* \mathrm{P}<0.05$ BHS vs BHR.

$(0.68 \pm 0.21)$ was also less than that in BHR $(0.99 \pm$ 0.1 ), but the difference was not significant.

AChE mRNA expression was significantly lower in tracheal smooth muscle from BHS compared to BHR. This result may partly relate to decreased AChE activity. In addition to tracheal smooth muscle, lung tissue was also studied because small airways were considered to be an important determinant of airway hyperresponsiveness in asthma $[6,16]$, but all mRNA expression was not similar in BHS and BHR. Because lung tissue contains alveolar tissue, pulmonary vessels and connective tissue, mRNA expressions may be affected by these nonairway cells. Moreover, AChE is derived from a single gene but occurs physiologically in various forms produced by alternative mRNA splicing or post-translational modification $[10,12]$. This splicing pattern may also cause a functional difference between BHS and BHR in AChE activity.

Although the predominant $(\sim 75 \%)$ cholinesterase in the smooth muscle is butyrylcholinesterase $(\mathrm{BuChE})$ $[2,3], \mathrm{AChE}$ has a much greater potential than BuChE [19]. A previous study has demonstrated that tracheal contractile responses to carbachol in vitro were similar in BHS and in BHR, but those to ACh were significantly greater in BHS than in BHR [18]. Takeuchi et al. [15] have also shown that AChE-positive nerves around bronchi are morphometrically greater in BHR than in BHS. Many studies suggested that the decrease in AChE activity may be associated with enhanced contractile response of tracheal smooth muscle to the exogenous and endogenous $\mathrm{ACh}$ in, for example, an active immune-sensitized dog model $[7,11,13]$. Because the present results were consistent with these studies, the decrease in AChE activity might also cause a stronger response to ACh in BHS. Bulut et al. [4] have reported that either $\mathrm{AChE}$ or BuChE activities in two mice strains (hyperresponsive $\mathrm{A} / \mathrm{J}$ and hyporesponsive $\mathrm{C} 3 \mathrm{H} / \mathrm{HeJ}$ ) were similar and were unlikely to contribute to the differences in airway responsiveness. Nevertheless, these mice strains were not selected on the basis of their bronchial contractile responses, so it might be very important that $\mathrm{AChE}$ activity is reduced in airway smooth muscle from BHS, which were selected as airway hyperresponsiveness models, in the clinical view of treatment for asthma.

In conclusion, this study has demonstrated that the decrease in AChE activity in airway smooth muscle might cause an increase cholinergic response. Congenital airway hyperresponsiveness in BHS may partly result from reduced $\mathrm{AChE}$ activity, and the cause of reduced AChE activity may be a decrease in AChE function and/or mRNA expression. The change in AChE activity may play an important role in the pathogenesis of airway hyperresponsiveness.

\section{References}

1. Adler, M. and Filbert, M.G. 1990. FEBS Lett. 267: 107- 
110.

2. Adler, M., Petrali, J.P., Moore, D.H., and Filbert, M.G. 1991. Arch. Int. Pharmacodyn. 312: 126-139.

3. Adler, M., Reutter, S.A., Moore, D.H., and Filbert, M.G. 1991. Eur. J. Pharmacol. 205: 73-79.

4. Bulut, Y., Kleeberger, S.R., and Hirshman, C. A. 1999. Exp. Lung Res. 25: 367-378.

5. Ewart, S.L., Mitzner, W., DiSilvestre, D.A., Meyers, D.A., and Levitt, R.C. 1996. Am. J. Respir. Cell Mol. Biol. 14: 487-495.

6. Haddad, E.B., Mak, J.C.W., Belvisi, M.G., Nishikawa, M., Rousell, J., and Barnes, P.J. 1996. Am. J. Physiol. 270: L947-L953.

7. Itabashi, S., Ohrui, T., Sekizawa, K., Matsuzaki, Y., and Sasaki, H. 1993. Respir. Physiol. 92: 219-225.

8. Levitt, R.C. and Mitzner, W. 1989. J. Appl. Physiol. 67: 1125-1132.

9. Levitt, R.C. and Mitzner, W. 1988. FASEB J. 2: 26052608.

10. Massoulie, J., Pezzementi, L., Bon, S., Krejci, E., and Vallette, F.M. 1993. Prog. Neurobiol. 41: 31-91.
11. Mitchell, R.W., Kelly, E., and Leff, A.R. 1991. Am. J. Respir. Cell Mol. Biol. 5: 56-62.

12. Nechushtan, H., Soreq, H., Kuperstein, V., Tshori, S., and Razin, E. 1996. FEBS Lett. 379: 1-6.

13. Ohrui, T., Sekizawa, K., Yamauchi, K., Ohkawara, Y., Nakazawa, H., Aikawa, T., Sasaki, H., and Takishima, T. 1991. J. Pharmacol. Exp. Ther. 259: 371-376.

14. Small, R.C., Good, D.M., Dixon, J.S., and Kennedy, I. 1990. Br. J. Pharmacol. 100: 516-522.

15. Takeuchi, S., Yoshimura, H., Go, K., Nishibata, R., and Mikami, H. 1996. Pathophysiology 3: 133-137.

16. Takishima, T., Yanai, M., and Sasaki, H. 1991. Am. Rev. Respir. Dis. 143 (Suppl): S49-S51.

17. Taylor, P. 1985. Cholinergic agonists. pp. 100-109. In: The Pharmacological Basis of Therapeutics (Gilman, A.G., Goodman, L.S., Rall, T.W. and Murad, F. eds), 7th ed., Macmillan, New York.

18. Yagi, Y., Kuwahara, M., Maeda, M., Kadota, H., Saegusa, S., Birumachi, J., Sugano, S., Nishibata, R., Mikami, H., and Tsubone, H. 1998. Exp. Anim. 47: 173-181. 